table. A great deal of ingenuity has gone into the construction of both tables and seismographs at Zurich, Stuttgart and elsewhere, and reports on the progress of the work, which is continuing, were given. For the general registration of earthquakes modern requirements are at least three components (northsouth, east-west and vertical $(Z)$ ), and it was emphasized that for the study of particular waves it is preferable to have all three components giving identical response (that is to say, with the same frequency characteristics).

It would be invidious to attempt to assess the importance of the papers presented at the meetings, but perhaps summaries of two may be given.

The first, by Dr. R. Teisseyre, of the Geophysical Institute of the Polish Academy of Sciences, described the mechanism of earthquakes in terms of dislocation theory. The basic assumptions are the existence of the non-hydrostatic part of the stresses in the medium $(P y 2)$ and the supposed distribution of the inhomogeneities (in the largest sense). This distribution includes some plane and its neighbourhood as the plane of active dislocation processes (slip plane, $y=0$ ). It has been shown by Dr. R. Teisseyre and Sophia Droste that the inhomogeneities can be represented by the loop dislocations in the presence of the field $P y 2$. The loop dislocations increase under the influence of the field $P y 2$, and by interaction between themselves (synthesis of loops). The slip area increases. Finally, when the dislocation reaches the Earth's surface its energy is discharged. The calculated energy of discharge is in good agreement with observational data.

In the second paper, Dr. H. Berckhemer (Stuttgart) discussed the influence of the movement at the focus of an earthquake on the seismic wave spectrum. Dr. Berckhemer first stated his method of separating the influence of happenings at the focus from the influences of the wave-path and the seismograph on the wave spectrum. It appears that when the magnitude of an earthquake increases, the longperiod wave spectrum is stimulated. Dr. Berckhemer explained this by theory and observation as being caused by extensive fault-breaks at the focus. His thesis is that it is possible to establish a connexion between the spread of the broken surface and the earthquake magnitude. This would make an important basis for the calculation of earthquake energy.

General impressions of the conference were, first, the intense interest of all present and the cut and thrust of very pointed discussion on all topics raised ; secondly, the shift of emphasis on problems being tackled-for example, the present interest in very great explosions for seismological purposes and the return of 'La Géologie Sismologique' as introduced by the late Comte de Montessus de Ballore-and thirdly, the tendency to specialization within seis. mology.

It is expected that a second series of great explosions will take place during the summer of 1958 in the French Alps, and also that an explosion of $30-40$ tons of explosive will be arranged to take place at a depth of some 300 metres in Belgium in September 1958. The elastic waves from these explosions will be recorded on seismograms and further knowledge obtained of the deeper structure of the Earth's crust. It is recommended that seismological stations obtain as soon as possible homegeneous sets of apparatus (recording three components having the same frequency characteristics) so as to be able to tackle seismological problems the more readily by direct comparison of the three components of vibration.

It is anticipated that the next meeting of the Commission will be held in Alicante during October 1959, when it is hoped that a symposium in collaboration with geologists will be held on seismotectonic problems, and another on the dynamical study of surface-wave problems.

The following were elected to office in the European Seismological Commission : President, Prof. P. Caloi (Rome); Vice-Presidents, Dr. J. Bonelli-Rubio (Madrid) and Prof. E. T. Savarensky (Moscow); Secretary, Mr. E. Peterschmitt (Strasbourg).

\section{E. TILlOTSON}

\title{
CLASSIFICATION OF BRACKISH AND INLAND SALINE WATERS
}

\begin{abstract}
$\mathrm{A}^{\mathrm{T}}$ $\mathrm{T}$ the International Congress of Limnology in Helsinki in August 1956, problems of brackish water were discussed and, at the suggestion of Prof. $\mathrm{S}$. Segerstråle, it was planned that a small group of specialists should be invited to attend a conference with the view of recommending a scheme of classification of brackish and inland saline waters which could be generally acceptable.

This conference was held during April 8-14 of this year at Venice under the joint auspices of the International Association of Limnology and the International Union of Biological Sciences. The place of meeting was the Centro di Studi Talassografici, the director of which, Prof. U. D'Ancona, is also president of the International Association. Papers were read by S. Segerstrăle (Finland), A. Remane (Germany), B. Havinga (Holland), M. Bãcescu (Roumania-in absentia), G. Petit and D. Schachter (France), U. D'Ancona (Italy), J. W. Hedgpeth (United States),
\end{abstract}

L. C. Beadle (Uganda), H. Caspers (Germany), D. J. Rochford (Australia - in absentia), W. Schmitz (Germany) and E. Dahl (Sweden). The conference was also attended by J. Dill, M. Girard and P. Job (Food and Agriculture Organization, Rome), by T. T. Macan (secretary of the International Association of Limnology), and by some Italian biologists (A. Marcello, B. Battaglia, A. Vatova and A. Giordani Soika).

The papers were concerned with the history of the subject, and with the ecology of brackish waters in the Baltic, Elbe estuary, Black Sea, the lagoons of southern France and the Adriatic, some Australian estuaries and of intertidal zones of the Scandinavian coasts. Inland saline waters in the southern United States of America, Germany and in North and East Africa were also discussed, and the physiological mechanisms for adaptation to brackish and saline waters were reviewed. 
The conference was very successful as a stimulating exchange of views and information on a subject, accounts of which have been very diffusely published and are thus difficult to collate.

At the final session a basic scheme was proposed for the classification of brackish waters which, in the opinion of the conference, would provide a useful framework of general application. It is based on zones of salinity of known biological significance and owes much to the earlier classifications of Redeke and Välikangas. Into this scheme more detailed sub-categories could be fitted to suit local conditions.

The proposed scheme is as follows:

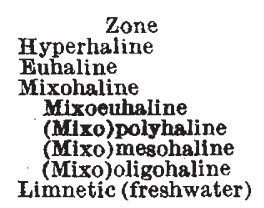

$$
\begin{aligned}
& \text { Salinity-range }(\%) \\
& >\sim 40 \\
& (\sim 40) \sim 40 \text { to } \sim 30 \\
& >\sim 30 \text { but less than adjacent euhaline sea } \\
& \sim 30 \text { to } \sim 18 \\
& \sim 18 \text { to } \sim 5 \\
& \sim \underset{5}{<} \sim 0.5
\end{aligned}
$$

For inland saline waters, it was agreed that no useful purpose could be served at present in devising a scheme of classification based on salinity zones. They are extremely variable in composition and several factors other than salinity are of great ecological significance. Moreover, our knowledge of them is as yet comparatively slight.

Venice is obviously a very suitable as well as delightful environment for a conference on this subject and, in spite of most unfavourable weather, excursions were made in and around the Venetian Lagoon. Here the technique of fish culture known as vallicoltura has been practised for many centuries and it involves some interesting problems in brackish water biology.

Through the generosity and hospitality of the Mayor of Venice, of the Venetian Tourist Association, of the Consorzio Vallicoltori, of Prof. D'Ancona and Prof. Alessandro Marcello, the members of the conference were able to enjoy much more than the biology of the Lagoon and were permitted to see many things of historic and artistic interest under expert guidance.

The proceedings of the conference will be published in Venice by the Centro di Studi Talassografici.

L. C. Beadle

\section{THE CARNEGIE TRUST}

T HE fifty-sixth annual report* of the Carnegie Trust for the Universities of Scotland, covering the year 1956-57, includes the report of the Executive Committee with a summary of grants for the ninth quinquennium, October 1, 1952-September 30, 1957, the abstract of accounts for the year ended September 30,1957 , and the report upon the work of investigators, with lists of publications by scholars and recipients of grants and assisted papers. No new research scheme was introduced during the year, but those in operation have yielded satisfactory results. The block grants to universities to assist staff whose research involves travel are regarded as invaluable, and also the scheme enabling ten members of the staffs of universities to study abroad for up to twelve months, under which, in 1956-57, a geologist worked in Greenland, an archæologist in Asia Minor, a philologist in Ethiopia, a physiologist, zoologist, philosopher and surgeon in America, a biochemist and botanist in Canada and a historian in France. Assistance was given in the publication of seven manuscripts submitted by Scottish graduates or members of the staffs of Scottish universities. No fellowship were awarded, but, besides four senior scholarships, 36 scholarships were renewed and 23 awarded in June 1957. The Executive Committee is concerned to remove anomalies which have been created between Department of Scientific and Industrial Research grants and those obtainable from the Scottish Education Department on one hand and Carnegie Scholarships on the other. Repayments by former beneficiaries totalled $£ 2,884$.

The report upon the work of investigators under the research scheme during the year refers particularly to J. Y. Thomson's continued work on the numerical evaluation of the boundary layer flow past a flat plate placed lengthwise to the stream; A. V. Gold on the de Haas-van Alphen effect in conductors at high magnetic fields; Dennis Mackay on the inter-

- Carnegie Fund for the Universitie of Scotland. Fifty-sixth Annual Report (for the year 1956-57) submitted by the puxecutive Committee to the Trustees on 24 th February, 1958 . Pp. iv 73 .
(Edinburgh : Carnegie Trust for the Universitfes of Scotland, 1968.) diffusion of the ions $\mathrm{Na}+, \mathrm{H}+$ and $\mathrm{Cl}-$, and also water across an ion exchange membrane; Donald Mackay on the decomposition of the peroxides of the organic acids ; and Iain M. T. Davidson on the dissociation of dibenzyl, in which he determined the kineties of the decomposition and the bond-strength of the central C-C bond. A. E. Scott in his study of the acid-base and thermal racemization of the ketols has shown that the activation energy of the former is approximately half that of the latter. I. D. R. Stevens continued work on the addition of dinitrogen tetroxide and nitryl chloride to substituted olefines and on the effects of substituents adjacent to the double bond on cis-and trans-additions, while J. F. MeKellar has identified the CHO, CH and $\mathrm{OH}$ radicals in the flash photolysis of acetaldehyde and formaldehyde both in absence and in presence of oxygen and is now studying the kinetics of their formation.

R. Logan has studied the influence of cytoplasm on the multiplication of ribonucleic and deoxyribonucleic acids in nuclear processes, using compounds labelled with carbon-14, and also the action of ultraviolet light and $\mathrm{X}$-rays, using nuclei from normal and regenerating rat-liver cells and from calf thymus. M. Los's attempts to find a general synthetic route for the $\beta$-quinindines and the $\beta$-pyrindines failed, but gave some interesting new compounds. Janet Buchanan's work on the herbarium material on the genus Luzula in Kew and Edinburgh is nearing completion, and Isobel C. Gardner's work on nitrogen fixation in root nodules of non-leguminous plants has shown that the American Myrica cerifora can be inoculated from $M$. gale and that nitrogen fixation is carried on by nodules so induced. G. K. Wellace's work on visual responses in locusts is a useful contribution to our knowledge of locust behaviour. Beatrice M. Blance's work on the origin and development of the Iberian Bronze Age and Elizabeth Burley's study on the archæological evidence for ScottishIrish connexions in the Dark Ages are specially commended. 